\title{
INFORME SOBRE LA ESTRUCTURA DEL HOSPITAL DE MAUDES
}

\author{
Francisco Couto Gulin, Arquitecto
}

\section{Estructura Metálica. Descripción}

Toda la estructura horizontal del edificio está realizada con elementos resistentes de acero laminado.

Cabe distinguir tres tipos de estos elementos:

1. Viga triangulada con cordón inferior curvo, situada sustentando la cubierta de las alas principales del edificio.

2. Viga en doble T de alma llena, formada por angulares y palastro. Sustenta los suelos de las plantas de uso de las alas antedichas.

3. Vigas en doble T de perfil simple. Entre éstas se pueden distinguir a su vez:

a) Viguetas formando forjado, apoyadas directamente en los muros.

b) Viguetas formando forjado, apoyadas sobre las vigas señaladas en los tipos 1 y 2 .

c) Viguetas apoyadas en el cordón inferior de la viga tipo 1 , formando techo curvo en las alas.

\section{Estado y tratamiento}

Vigas tipo 1

En los numerosos puntos en que se ha dejado al descubierto este tipo de estructura, se ha podido observar que no presenta deformaciones apreciables a simple vista ni con medios de medida manual. El estado de las propias vigas, asi como los planos por ellas sustentados, y los encuentros con el resto del edificio, hacen pensar en una situación de estabilidad y resistencia correctas.
El estado del material, por el aspecto que ofrece a la observación, es de una corrosión poco profunda en general, exceptuándose algunos puntos localizados -de entre los actualmente visibles - en que se puede apreciar un avance mayor de la corrosión.

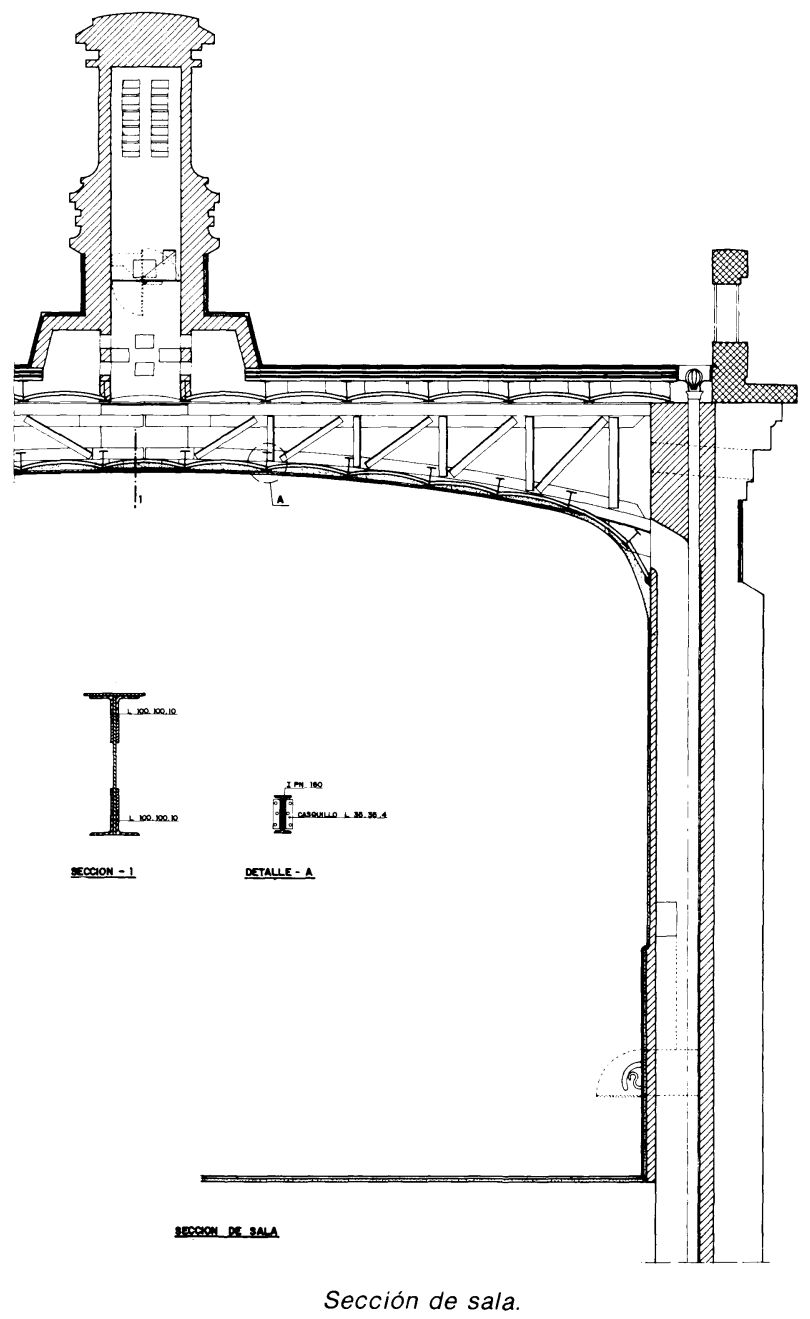




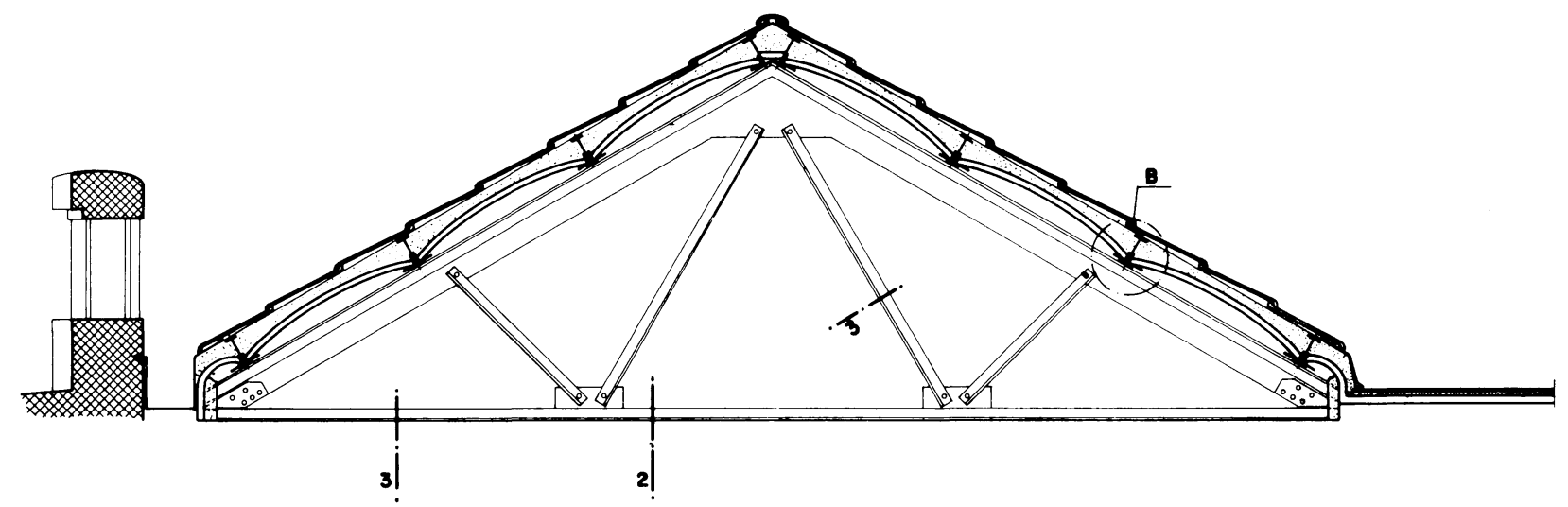

SECCION CUEIERTA TENA PLAMA



SECCION -3

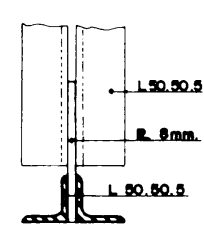

$\operatorname{seccon}-2$
De los tanteos realizados, peritaciones de las piezas según las cargas a que se encuentre sometida y las nuevas que se han de producir por la rehabilitación de la cubierta, se deduce su idoneidad, quedando la estructura lista para su servicio una vez subsanadas las deficiencias locales producidas por corrosión de piezas.

Se está sometiendo la estructura en general a un análisis de laboratorio solicitado al Centro Nacional de Investigaciones Metalúrgicas; los resultados obtenidos hasta el momento nos muestran una gran segregación, debido al alto contenido fosfórico $(0,078 ; 0,12 ; 0,115)$ y de azufre $(0,09 ; 0,087 ; 0,13)$. Lo que nos obliga a restringir el uso de soldaduras a casos y puntos muy concretos.

En conclusión, respecto a este tipo de vigas se hará lo siguiente: descubrirlas completamente, proceder a su limpieza hasta alcanzar el metal totalmente sano, reforzar, si hubiera necesidad de ello, los puntos en que la corrosión hubiera afectado alguna pieza, proteger las superficies ya limpias y saneadas para evitar el avance de nuevas corrosiones.

\section{Vigas tipo 2}

El estado es prácticamente el mismo que en el tipo anterior, siendo en este caso la corrosión muy superficial en todos los puntos observados.

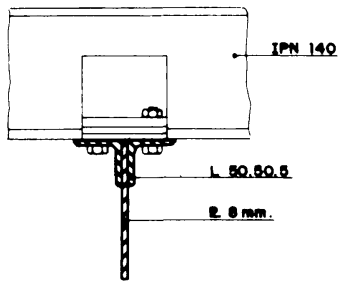

SECCION-4

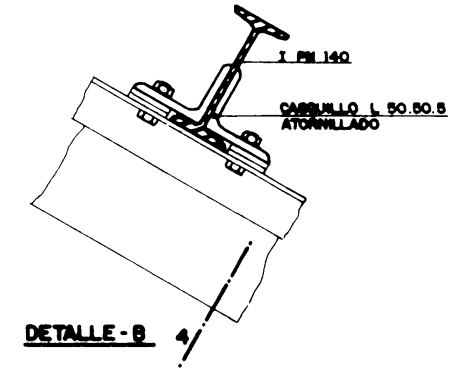

De los cálculos realizados se desprende la necesidad de reforzar dichas vigas para adaptarlas a las sobrecargas que le imponen los nuevos usos del edificio. Para ello se tienen en cuenta los resultados del laboratorio anteriormente expuestos. El tipo de refuerzo y su justificación se expone más adelante.

En este caso también se descubrirá totalmente la viga para proceder a su limpieza, tras la pertinente actuacion de refuerzo, y a su protección anticorrosiva.

En los lugares de la planta inferior en que las bajantes descalzan los apoyos, se procederá a su estabilización, pues aunque el apoyo fuese suficiente, se ha de evitar la excentricidad de las reacciones que podría dar lugar a esfuerzo de torsión.

\section{Vigas tipo 3}

Entre este tipo de viguetas, las del grupo a), parecen las más afectadas. Entre las pertenecientes a corredores que, por su poca luz pudieran producirse grandes daños, se plantea la sustitución de las que presentan un grado de corrosión que las convierte en ruinosas. Aquellas en que la corrosión sea sólo superficial han de ser limpiadas hasta encontrar el metal sano y posteriormente protegidas contra la corrosión, evitando el 


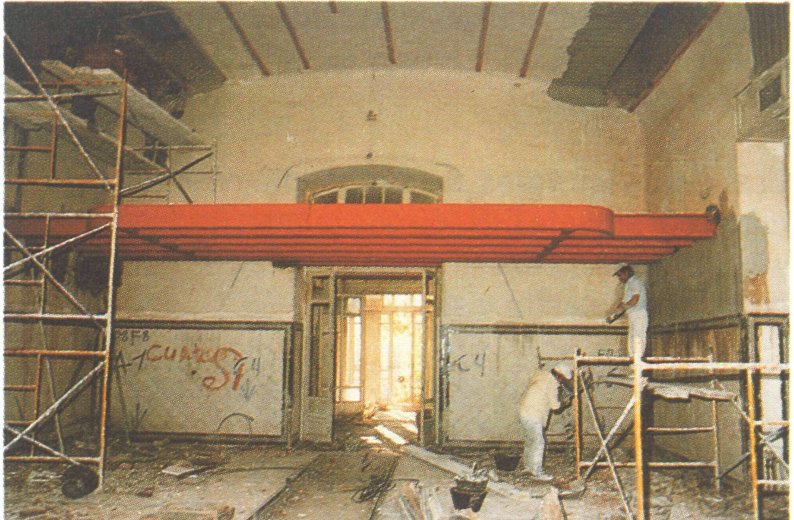

levantamiento completo a la apertura de catas en los lugares en que se aprecian signos de agresiones por humedad. Esto mismo se hará en las del grupo b).

En los cuerpos del edificio, a ambos lados del patio cuadrado, se realizará la sustitución del forjado completo en las plantas más afectadas. En las muestras Ilevadas al laboratorio se apreció una pérdida del $50 \%$ de la sección en algunos puntos. Para el grupo c) (tipo 1) se limpiarán quitando todo rastro de oxidación y se protegerán con el tratamiento anticorrosivo que se determina: dos manos de minio electrolítico homologado por el INTA.

\section{Aspectos puntuales a señalar}

La conexión de las vigas triangulares (tipo 1) con los muros, se encuentran con un deterioro producido por la incompatibilidad de deformaciones. El giro de la viga ha arrastrado parte de la fábrica de ladrillo en su movimiento produciendo un pequeño agrietamiento que disgrega la fábrica del resto. No nos parece inquietante pero hemos de señalarlo para su seguimiento y observación.

\section{Actuaciones de reparación}

En el edificio se han producido algunos deterioros imputables en nuestra opinión al propio diseño y algunos por deficiente previsión constructiva. Cabria señalar:

La escalera de entrada principal por la calle de Maudes ha sufrido un asiento que se manifiesta en su cizallamiento respecto al edificio. La rotura no se ha producido en los peldaños por ser éstos independientes. No obstante existe una tabica con mayor altura por la holgura existente. La reparación nos parece innecesaria pues sería gravosa en estos momentos en que además suponemos el movimiento estabilizado. Queda pues señalado para su seguimiento.
Los ábsides del pabellón de la calle Alenza no llegan al sótano. El suelo de su planta principal queda así asentado sobre el terreno, a diferencia del resto de la planta que está sobre forjado. Esto ha dado lugar a un hundimiento de los suelos de dichos ábsides que hemos de reparar levantándolos y rehaciéndolos sobre un forjado de nueva ejecución.

Pabellón de Treviño tiene, en la fachada que da a la calle Maudes y en los dos ábsides, huecos de gran luz, haciendo concentrarse el gran peso de la edificación en machones que al asentar no han sido acompañados por la zona de las ventanas, produciéndose así agrietamientos en los alfeízares y antepechos.

Las cuatro grandes naves de la edificación se encuentran moduladas a 4,50 metros, manifestándose en el exterior la modulación por el juego de vanos y macizos, señalándose en estos contrafuertes que son según se asciende, más esbeltos. A los contrafuertes exteriores corresponden en el interior los apoyos de las vigas. Al Ile;gar a ambos extremos de las naves los contrafuer'es persisten, pero las vigas ya no existen, encomendándose su función a los diafragmas de fábrica que cierran dichos extremos.

Esta solución nos está produciendo dos consecuencias:

Una primera es que el último tramo de viguetas a cada extremo de las naves, en lugar de ser de $4,50 \mathrm{~m}$ es de $6,5 \mathrm{~m}$ con el consecuente aumento de la carga sobre la viga y el diafragma. A su vez sobre las zonas extremas de las naves se encuentran situados los Torreones, lo que significa un considerable aumento de peso. Esto, unido a que el diafragma está perforado por numerosos huecos, hace que hayan aparecido grietas rasgando éstos en su centro y arrastrando las paredes laterales de la zona extrema exterior, con su consecuente agrietamiento. Lo único que cabe hacer para corregir esta situación es coser las grietas existentes y eso es lo que se proyecta.
El nuevo uso del edificio nos obliga, cumpliendo la normativa actual, a un refuerzo en algunas de las zonas de la estructura.

El suelo de las naves, anteriormente descrito, está formado por viguetaIPN-160 que cubren las luces de 4,50 y 6,50 metros. Estas se apoyan sobre una doble T compuesta de palastro y angulares.

La peritación de viguetas y vigas que a continuación se detallan, evidencia la necesidad de los refuerzos que se diseñan.

Se realizará la sustitución del suelo existente, pasando la evaluación de cargas que planteamos, de acuerdo con el nuevo suelo y con la MV-101.

\section{publicaciones del I.E.T.C.C.}

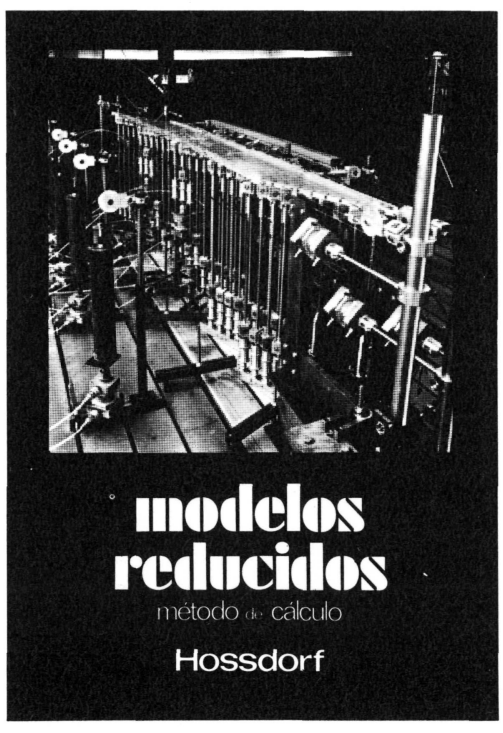

Modelos reducidos. Método de cálculo

H. Hossdorf, Ingeniero Civil

La técnica de los ensayos en modelos reducidos de estructuras sufre hoy dia una decisiva metamorfosis. Hasta hace poco era un medio más bien de artesania, que no siempre era tomado en serio por los académicos teorizantes para comprender el comportamiento resistente de las estructuras complejas y al que se acudió las más de las veces, como a un último remedio debido a sus indiscutibles insuficiencias. Sin embargo, en poco tiempo y gracias a su conexión con los ordenadores digitales, se ha transformado en un instrumento cientificamente valioso, que no puede quedar a un lado en la práctica diaria del Ingeniero Proyectista.

Un volumen encuadernado en cartoné plastificado con lomo de tela, de $17 \times 24 \mathrm{~cm}$, compuesto de 250 páginas, 158 figuras y fotografias.

Precios: 1.800 ptas.; \$ USA 26.00 .

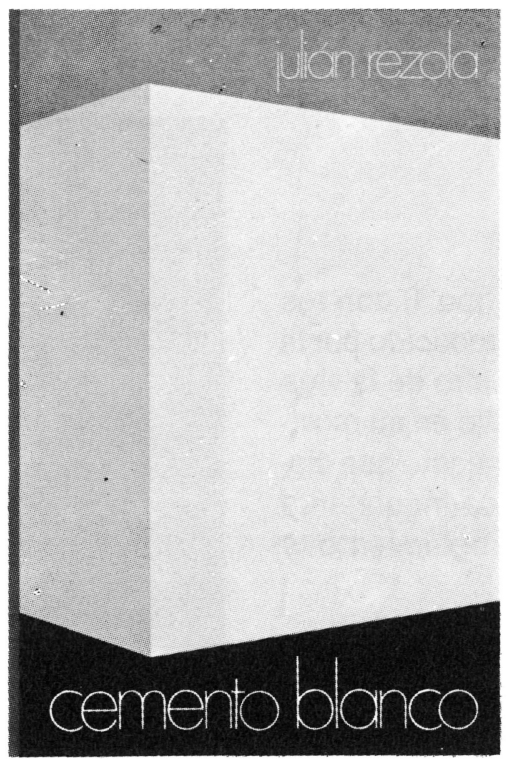

Cemento blanco

Julián Rezola

Ingeniero Químico Dipl. I. Q. S.

Sabido es que existe una extensa y documentada bibliografia sobre el cemento gris: en cambio, no puede decirse lo mismo acerca del cemento portland blanco, ya que los escritos existentes se refieren tan sólo a algunas peculiaridades que le distinguen de aquél.

El autor nos ofrece sus profundos conocimientos y su larga experiencia tanto en laboratorio como y su larga exper

La parte descriptiva del libro se complementa con gráficos, diagramas y fotografías de gran utilidad, destinados a conseguir la aplicación apropiada de este aglomerante.

Un volumen encuadérnado en cartoné policerado, de $17,4 \times 24,3 \mathrm{~cm}$, compuesto de 395 páginas numerosas figuras, tablas y ábacos.

Precios: España, 1.700 ptas.; extranjero, \$ 24.

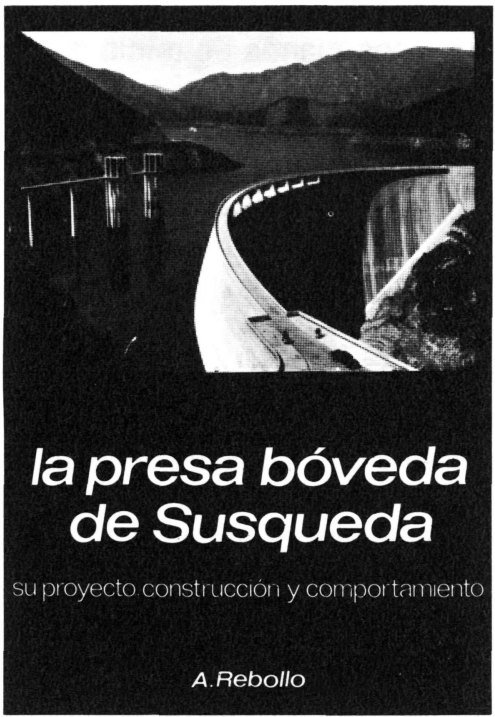

La presa bóveda de Susqueda A. Rebollo,

Dr. Ingeniero de Caminos

El esfuerzo del constructor de presas se sitúa, por su pretensión de perennidad, a contracorriente rizada por lo fungible. Pueden evocarse las 10.000 grandes. presas en funcionamiento o en construcción que están envejeciendo y reclaman los cuidados gerontológicos para mantener y perfeccionar su servicio y garantizar su inalienable pretensión de perennidad. En la medida en que todas nuevas obras, grandes o pequeñas, son portadoras de riesgos ecológicos $y$, a veces, catastróficos, que aumentan con el envejecimiento, la gerontologia de las presas es todo un emplazo. La acción adelantada de Arturo Rebollo en este terreno marca un camino a seguir para todos los que aman su propia obra con la devoción paternal que el ha puesto en Susqueda.

Un volumen encuadernado en cartoné plastificado con lomo de tela, de $18 \times 24,5 \mathrm{~cm}$, compuesto de 408 páginas, 330 figuras $y$ fotografias $y 39$ tablas.

Precios: 1.700 ptas.; extranjero, \$ USA 24.00. 